\title{
Lead Free BNBT Type Ceramics: A Useful Material for Sensors and Ultrasound Applications
}

\author{
E. Suaste Gómez and J. J. A. Flores Cuautle \\ Centro de Investigación y de Estudios Avanzados del Instituto Politécnico Nacional \\ México
}

\section{Introduction}

Ferroelectric, piezoelectric and pyroelectric materials, belong to the family called smart materials and have been extensively studied for several years, not only because they have interesting physical phenomena but also because it can be used in wide variety of applications in the most diverse fields, ranging from the automotive industry as temperature or pressure sensors, even in scientific circles as polarizers or light waveguide modulators (Moulson and Herbert, 2003).

Among the smart materials most widely used are those based on combinations of lead titanate $\left(\mathrm{PbTiO}_{3}\right)$ and lead zirconate $\left(\mathrm{PbZrO}_{3}\right)$, leading to the formation of so-called lead zirconate-titanate (PZT), PZTs for many years has been that present the best piezoelectric and pyroelectric characteristics, however due to environmental efforts in different countries are doing, such as the Directive of the European Parliament and the Council on restriction of the use of certain hazardous substances in electrical and electronic equipment, and the restriction of hazardous substances in the USA, it is necessary to enforce research in order to find materials to replace the PZTs.

There are no materials that display the excellent characteristics that PZT presents that is why in order to replace PZT system it is necessary to divide applications and develop materials which suite for each application. Several lead free materials have been studied as possible replaces for PZT; barium titanate $\mathrm{BaTiO}_{3}$ (BIT) is one of the most studied ferroelectric oxide with perovskite structure, it has been used in piezoelectric applications such as sonar due to its high electromechanical coupling factor, however BIT has low Curie temperature $\left(\mathrm{T}_{\mathrm{c}}=\right.$ $\left.120^{\circ} \mathrm{C}\right)$, (Jaffe, 1971).

Potassium niobate $\mathrm{KNbO}_{3}$ is another lead free ferroelectric material with high $\mathrm{T}_{\mathrm{c}}\left(425^{\circ} \mathrm{C}\right)$ but to obtain dense ceramic body requires long soaking time (Jaeger \& Egerton, 1962). The bismuth sodium titanate $\left(\mathrm{Bi}_{0.5} \mathrm{Na}_{0.5}\right) \mathrm{TiO}_{3}(\mathrm{BNT})$ is an excellent candidate for use in lead-free ferroelectric ceramics because BNT is strongly ferroelectric and has a high Curie temperature $\left(\mathrm{T}_{\mathrm{c}}=320^{\circ} \mathrm{C}\right.$ ) (Smollenky et al., 1961; Buhrer, 1962). However data on BNT properties are scarce due to the difficulty in poling process for these ceramics. Recently BNT-based solid solutions which can be poled easily have been studied (Takenaka et al., 1989, 1991; Sasaki et al., 1999; Rajeev \& Dviwedi, 2005). 
Lately $\left(\mathrm{Bi}_{0.5} \mathrm{Na}_{0.5}\right)_{0.935} \mathrm{Ba}_{0.065} \mathrm{TiO}_{3}$ ferroelectric ceramics have been develop (Suaste et al., 2008), this type of ceramics present high $\mathrm{T}_{\mathrm{c}}$, high dielectric constant at this point, excellent density, pyroelectric coefficient at room temperature (RT) near to lead titanate, thermal properties at RT near to those of BIT, in addition this type of ceramics present photovoltaic response not only to a visible light but also to near UV light, these characteristics joining with its lead free composition makes this material an option of choice to develop sensors and actuators. In this chapter we describe the development, electrical and thermal characterization of $\left(\mathrm{Bi}_{0.5} \mathrm{Na}_{0.5}\right)_{0.935} \mathrm{Ba}_{0.065} \mathrm{TiO}_{3}$ (Gonzalez \& Suaste, 2009, Flores et al., 2009), and at the same time present an ultrasound application for this material.

\section{Fabrication}

To ensure that the perovskite structure is stable, we must consider the size of the ionic radii of the cations that constitute such structure, which is expressed in the so-called tolerance factor $t$, the tolerance factor is given by the equation 1

$$
t=\frac{R_{A}+R_{o}}{\sqrt{2}\left(R_{B}+R_{o}\right)}
$$

Where $R_{A}$ is the divalent cation ionic radius for our formulation this site is occupied by bismuth $(\mathrm{Bi})$, sodium $(\mathrm{Na})$ and barium $(\mathrm{Ba}), \mathrm{R}_{\mathrm{B}}$ is the ionic radius of tetravalent cation titanium (Ti) and $\mathrm{R}_{\mathrm{O}}$ is the ionic radius of oxygen, the tetragonal structure is ensure with $t$ values between 0.77 and 0.99 , in the case of a cubic structure this factor takes a value of 1 , for our ceramic $t$ has a value of 0.84 .

Starting from the formulation $\left(\mathrm{Bi}_{0.5} \mathrm{Na}_{0.5}\right)_{1-\mathrm{x}} \mathrm{Ba}_{x} \mathrm{TiO}_{3}$ is necessary to calculate the value of $x$, this is done taking into account two main points: the first is to ensure that the final compound is in the interest region in its phases diagram, the second is to found the $x$ value that makes calculations easier, in our case $x$ has a value of 0.065 .

Ceramic samples were prepared by a conventional solid state reaction, reagent-grade powders of oxides and carbonates with $99+\%$ purity of $\mathrm{Bi}_{2} \mathrm{O}_{3}, \mathrm{NaCO}_{3}, \mathrm{BaCO}_{3}$, and $\mathrm{TiO}_{2}$ were used as starting raw materials. These materials were weighted in appropriate portions, mixed and calcined at $800^{\circ} \mathrm{C}$ during one hour, after calcining the ceramic powders were grounded, milled and pressed into disks of $10 \mathrm{~mm}$ in diameter and about $1.9 \mathrm{~mm}$ in thickness. These disks were sintered at $1200^{\circ} \mathrm{C}$ for one hour in air. Once samples were sintered, fired-on silver paste was used as electrodes in order to measure their electric properties. Finally, the samples were poled at $60^{\circ} \mathrm{C}$ in a silicone oil bath by applying a dc electric field of $3 \mathrm{kV} / \mathrm{mm}$ for 1 hour.

\section{Characterization}

\subsection{Structure characterization}

In order to verify the ceramic structure a SEM micrograph with a magnification of 5000X and resolution of 1 micrometer was taken. Ceramic density was measured by the Archimedes method the average density was $5.6 \mathrm{~g} / \mathrm{cm}^{3}$. Figure 1 shows a SEM image of BNBT ceramic taken at 5000X with a $1 \mu \mathrm{m}$ scale bar, micrograph shows that the ceramic has a compact structure with few impurities that no affects the ceramic behaviour, compact structure join to ceramic density of $5.6 \mathrm{~g} / \mathrm{cm}^{3}$ pointed out that this material may be optimal for transducers. The crystal structure of the ceramics was examined by the use of X-ray 
diffractometer, as Fig 2 shows, XRD pattern is in agreement with the reported literature (Rajeev \& Dviwedi, 2005; Weihua et. al., 2008).

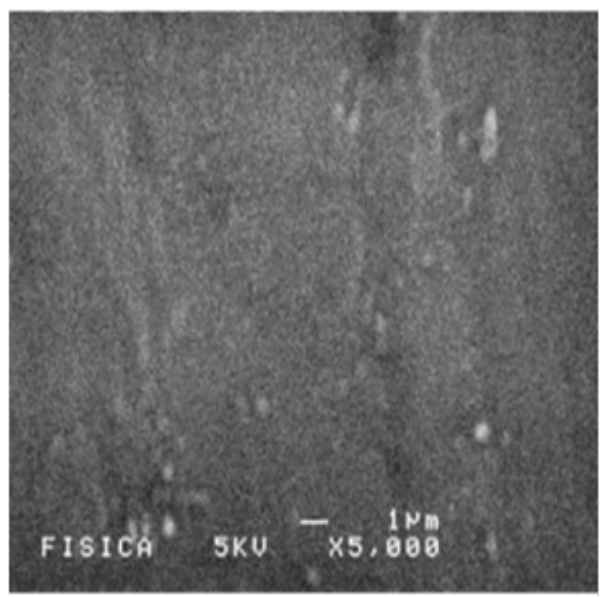

Fig. 1. Piezoelectric ceramic SEM image taken at 5000X and $1 \mu \mathrm{m}$ scale bar

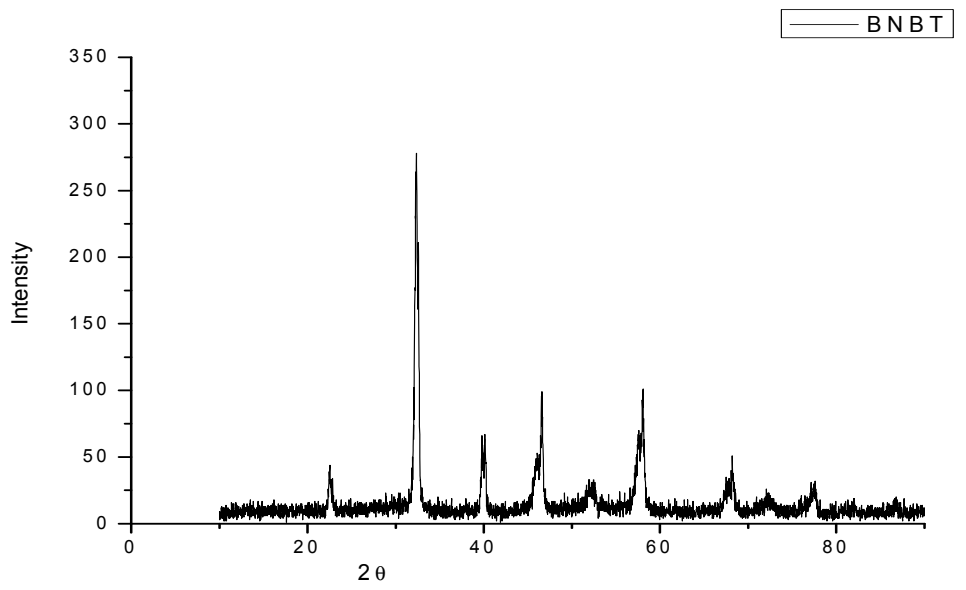

Fig. 2. XRD pattern of the ceramic specimen

\subsection{Electrical characterization}

The dielectric constant was determined by the capacitance measure. Samples were heated at a rate of $5^{\circ} \mathrm{C} / \mathrm{min}$, until $600^{\circ} \mathrm{C}$ while the capacitance was measured at $1 \mathrm{kHz}$ with a Beckman LM22A RLC bridge. The dielectric constant was then determined by expression (2):

$$
\varepsilon=\frac{C l}{\varepsilon_{0} A}
$$


Where $C$ is the capacitance in $F, l$ is the sample thickness in $m, A$ the sample area in $m^{2}$ and $\varepsilon_{0}$ the vacuum permittivity $=8.85 \times 10^{-12} \mathrm{~F} / \mathrm{m}$.

The resonance frequency was determined by the transmission method described by the IRE Standards [IRE Standard on piezoelectric crystals, 1961], the experimental setup consist in a voltage divisor formed by ceramic and one load resistance fed by a signal generator, an oscilloscope was connected to the resistance as Fig 3 shows. A frequency sweep was performed; the resonance frequency is then presented as an increase in signal amplitude, this is due to the ceramic impedance is minimum at this point consequently current trough circuit is maximum, in the same way the antirresonance frequency was found. These frequencies were also measured with an Agilent E4411B spectrum analyzer

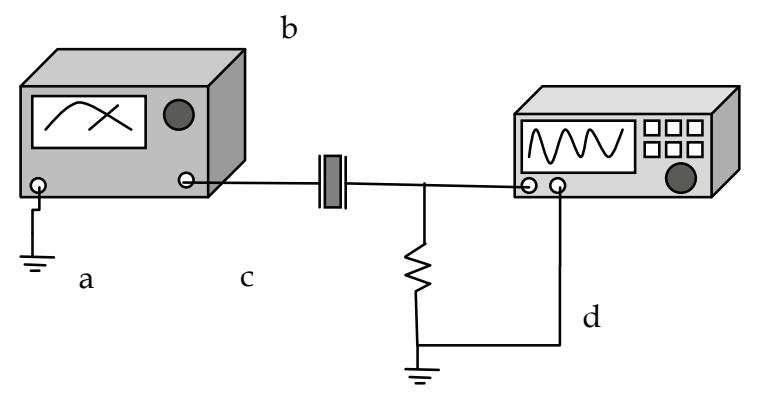

Fig. 3. Experimental setup used to get resonance and antiresonance frequency, a) generator, b) piezoelectric ceramic, c) load resistance and, d) oscilloscope

Coupling factor $k_{p}$ was obtained by using IRE Standard [IRE Standard on piezoelectric crystals, 1961], which relates resonance and antiresonance frequency in form of the equation 3

Where $f_{r}=$ resonance frequency

$$
k_{p}=\frac{f_{a}-f_{r}}{f_{r}}
$$

$f_{a}=$ antiresonance frequency

For the thickness coupling factor $k_{t}$ the Onoes method was used (Onoe \& Tiersen, 1963). The method involves to find the fundamental resonance frequency and the first four harmonics, divide each of the harmonic frequencies between the fundamental and seek the coefficients obtained in the table given by Onoe.

The dielectric constant was determined using equation 2; Fig 4 shows the dielectric constant dependence with the temperature. $\mathrm{T}_{\mathrm{c}}$ occurs at $425^{\circ} \mathrm{C}$ that is a relatively high temperature for ceramics, at this temperature dielectric constant reach its maximum value $\varepsilon=4429$, a large value compared with other lead free ceramics.

As previously was mentioned the resonance frequency depends on the ceramic thickness, Fig 5 shows the resonance spectrum ranging from $100 \mathrm{~Hz}$ until $15 \mathrm{MHz}$ for a BNBT ceramic with $1.9 \mathrm{~mm}$ thickness taken with a spectrum analyzer, theoretical frequency resonance was calculated by the use of equation 4 (Efimovich, 1964)

$$
f=\frac{c}{\lambda}
$$


Where $\mathrm{c}$ is the phase velocity and $\lambda=2 l$ with $l$ ceramic thickness, in order to find phase velocity the equation 5 was use (Efimovich, 1964)

$$
c=\frac{1}{\sqrt{s \rho}}
$$

where $s$ is the elastic constant and $\rho$ ceramic density, for this type of ceramics $s=8.59 \times$ $10^{12} \mathrm{~m}^{2} \mathrm{~N}^{-1}$ and $\rho=5.6 \times 10^{3} \mathrm{kgm}^{-3}$ (Takenaka et al., 1991; Suaste et al., 2008), theoretical resonance frequency was $1.2 \mathrm{MHz}$ which is near to the measurement frequency as it can be seen in Fig 5.

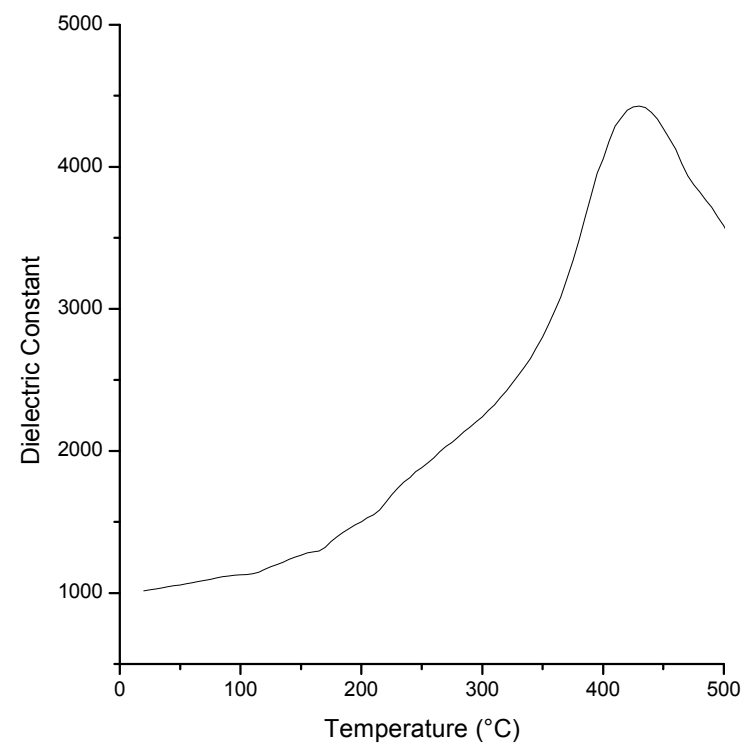

Fig. 4. Dielectric constant characterised by temperature for BNBT ceramics. The Curie temperature is reached at $425^{\circ} \mathrm{C}$

The electromechanical coupling factors $k_{p}$ and $k_{t}$ were measure for some samples, the average values were: $k_{p}=6.68$ and $k_{t}=0.588$.

Pyroelectric coefficient (Pi) was found by the used of Byer and Roundy method, the ceramic was placed into a programmable oven and temperature was increased gradually, the electrodes were connected to a resistance and voltage drop on the resistance was measured with a high sensibility multimeter (Byer \& Roundy, 1972); for pyroelectric detectors the relationship between pyroelectric coefficient and permittivity is calculated with the expression 6 (Liu et at., 1975)

$$
\frac{p_{i}}{\sqrt{\varepsilon}}
$$


where $p_{i}$ is the pyroelectric coefficient and $\varepsilon$ is the permittivity, for many pyroelectric materials, the ratio $P i / \sqrt{\varepsilon}$ tends to be constant and has a value of $(3.0 \pm 1.0) \times 10^{-9} \mathrm{CK}^{-1} \mathrm{~cm}^{-2}$ (Liu et at., 1975) and is an indicator of how good pyroelectric detector is the material, Table 1 shows permittivity, pyroelectric coefficient and this ratio for BNBT ceramic as well as BIT in order to compare it.

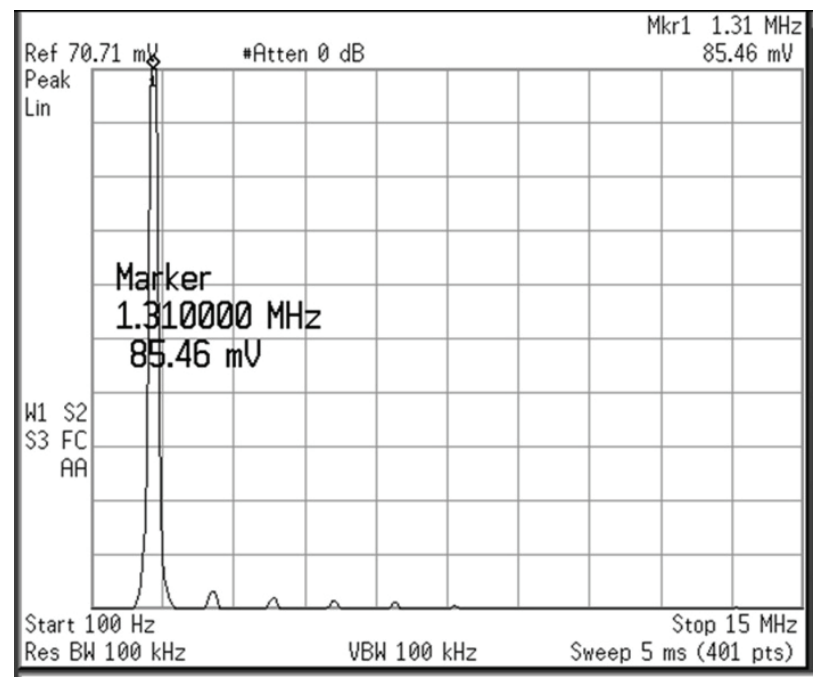

Fig. 5. Resonant frequency $(1.31 \mathrm{MHz})$ of a piezoelectric ceramic with a $1.9 \mathrm{~mm}$ thickness in a logarithmic scale

\begin{tabular}{llll}
\hline Material & $\varepsilon$ & $P i\left(10^{-9} \mathrm{CK}^{-1} \mathrm{~cm}^{-2}\right)$ & $P i / \sqrt{\varepsilon}\left(10^{-9} \mathrm{CK}^{-1} \mathrm{~cm}^{-2}\right)$ \\
\hline $\mathrm{BaTiO}_{3}$ & 160 & 20 & 1.58 \\
$\left(\mathrm{Bi}_{0.5 \mathrm{Na}} \mathrm{Na}_{0.5}\right)_{0.935 \mathrm{Ba}_{0.065} \mathrm{TiO}_{3}}$ & 1185 & 49.6 & 1.44
\end{tabular}

Table 1. Room temperature dielectric constant, pyroelectric coefficient and the relationship for pyroelectric detectors of $\mathrm{BNBT}$ and $\mathrm{BaTiO}_{3}$ (Lines \& Glass, 1979; Suaste et al., 2008)

\subsection{Optical characterization}

In order to probe the ceramic response to the ultraviolet light, ceramic was submitted to a frequency modulated UV light, while the voltage response was monitoring. The experimental setup consist in a UV lamp with an illuminance of 1 lux and peaks at $365 \mathrm{~nm}, 404$ $\mathrm{nm}$ and, $436 \mathrm{~nm}$ wave-length, a mechanical chopper modulates the light at a $22 \mathrm{~Hz}$ frequency and this modulated light was coupled to the ceramic by the use of an optic fiber to one side with electrical transparent contact made with indium oxide, by the use of a tuned amplifier and oscilloscope ceramic signal was obtained, experimental setup is show in Fig 6. 


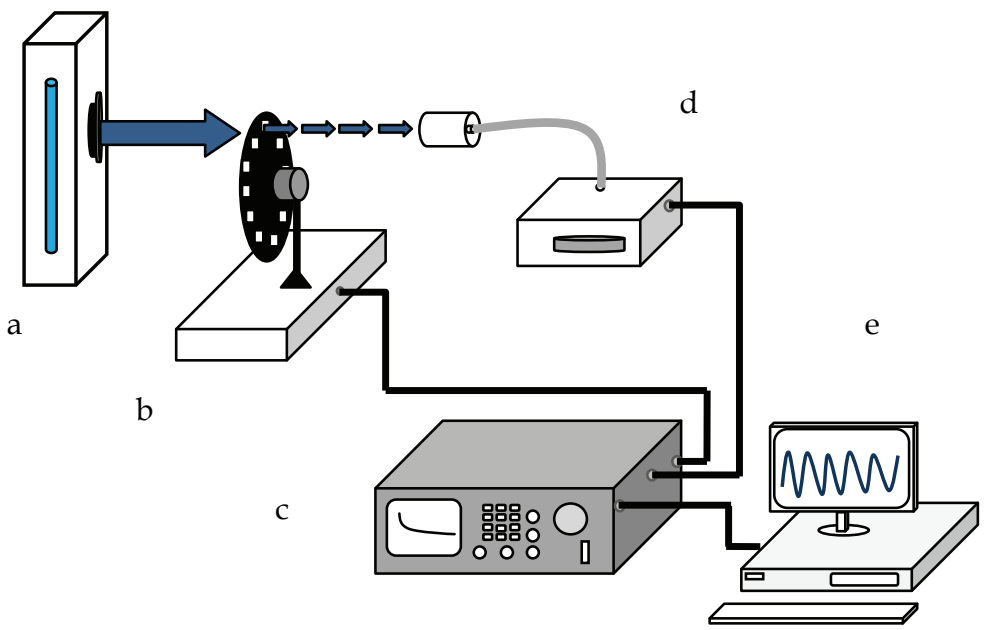

Fig. 6. Experimental setup used to obtain ceramic response to UV light at different temperatures, a) UV lamp, b) chopper, c) tuned amplifier, d) BNBT ceramic, e) personal computer

Photovoltaic BNBT ceramic response when is stimulated with visible light was found (Suaste \& Gonzalez, 2009), by the ceramic stimulation with near UV light it was probed that ceramic presents electrical response to near UV light range as Fig 7 shows.

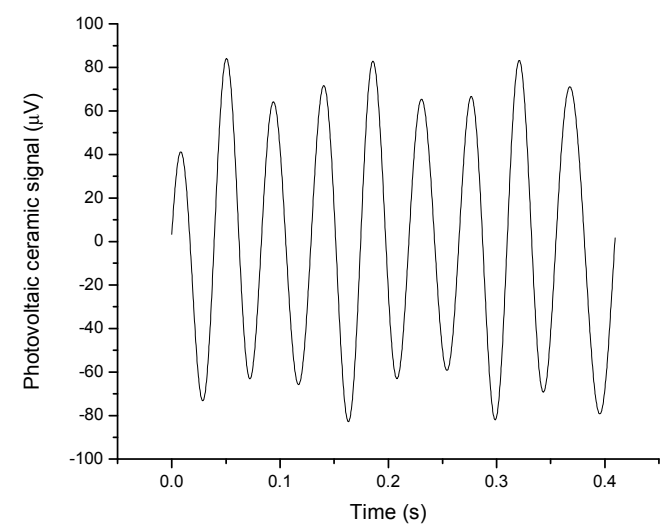

Fig. 7. Photovoltaic ceramic signal under near UV light stimulation

\subsection{Thermal characterization}

It is well known that thermal diffusivity is a physical quantity extremely sensitive to the composition and structure of materials (Rosencwaig, 1980; Calderon et al., 1997), and also depends on the processing conditions, is why it was done a measure of this physical quantity as well as thermal effusivity. 
The measurements of thermal characteristics were performed using the open photoacoustic cell (OPC) (Marquezini et al., 1991; Cruz et al., 1996) and inverse photopyroelectric (IPPE) techniques (Caerels et al., 1998). The experimental setup employed to obtain the sample thermal diffusivity ( $\alpha$ ) consisted of $100 \mathrm{~mW}$ argon (Ar) laser whose light beam was mechanically modulated with a chopper and focused into the sample as shown in Fig 8 . The sample (e) was fixed with vacuum grease (f) upon the inlet of an electret microphone formed by g-j sections as shown. The microphone output signal was amplified by a lock-in amplifier (c) and the amplitude and phase were measured as function of light modulation frequency.

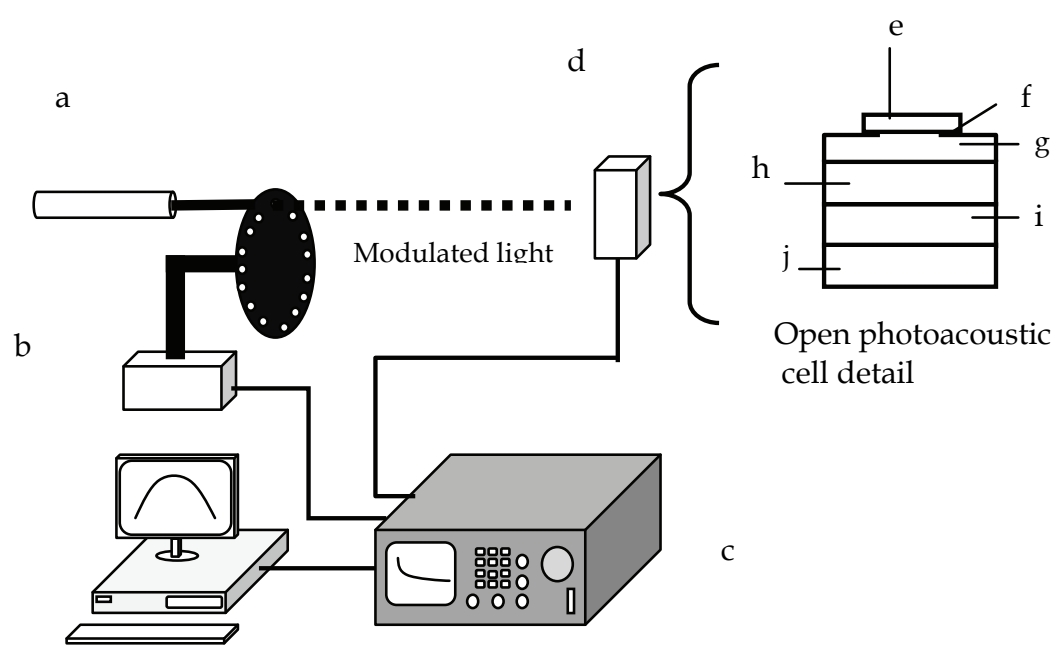

Fig. 8. OPC experimental setup a) Laser, b) chopper, c) lock-in amplifier, d) open photoacoustic cell, e) ceramic sample, f) vacuum grease, g) photoacoustic chamber, h) metalized electret diaphragm, i) air gap, j) metallic back plate

The theoretical expression (7) for the OPC in the heat transmission configuration, for optically opaque and thermally thick samples (i.e. $l_{s} a_{s} \gg 1$, where $l_{s}$ is the sample thickness and $a_{s}=\sqrt{\pi f / \alpha_{s}}$ ), used to fit the experimental values is (Marquezini et al., 1991):

$$
V_{O P C}=V_{O} \frac{j \omega R C}{1+j \omega R C} \frac{I_{0} \exp \left(-l_{s} \sigma_{s}\right) \exp (j \omega t)}{T_{0} l_{g} \sigma_{g} k_{s} \sigma_{s}}
$$

Where $\mathrm{V}_{\mathrm{OPC}}$ is the OPC voltage obtained from the electret microphone, $\mathrm{RC}$ is the time constant of the microphone, $l_{s}$ is the sample thickness, $\omega$ is the modulation frequency in $\mathrm{rad} / \mathrm{s}, \sigma_{i}=(i+j) \sqrt{\pi f / \alpha_{i}}$, with $j=\sqrt{-1}$ and $\alpha_{i}$ is the thermal diffusivity of medium $i$, with $i=g$, $s$ (gas and sample respectively).

In order to obtain the thermal effusivity the experimental setup showed in Fig 9 was used which consists of a Helium-Neon (He-Ne) laser whose light beam was modulated by an acousto-optic modulator. The sample was fixed with thermal grease upon the pyroelectric detector. The pyroelectric signal was amplified with a lock-in amplifier and the amplitude and phase were measured as a function of $f$. 


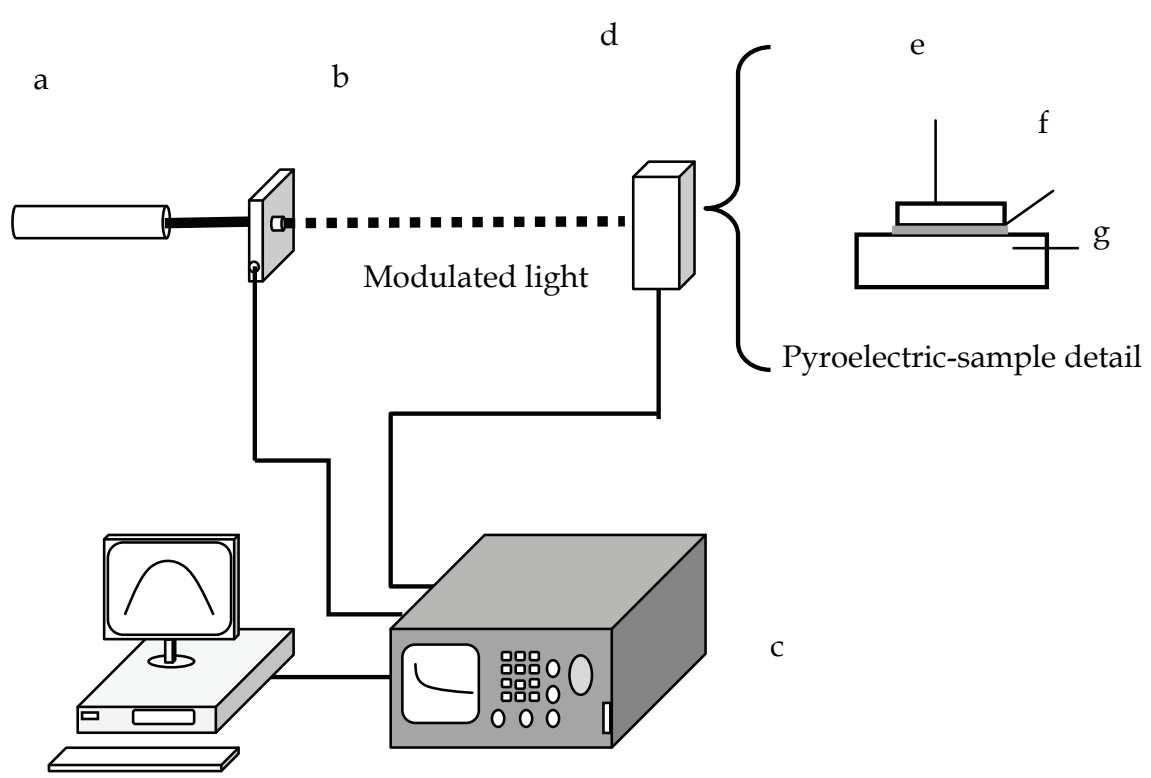

Fig. 9. Experimental setup used to obtain the IPPE signal a) Laser, b) acousto-optic modulator, c) pyroelectric-sample, d) lock-in amplifier, e) sample, f) thermal grease, g) pyroelectric sensor

For the IPPE geometry, when is assumed a thermally thick sample, the theoretical expression (8) used to fit the experimental data is (Glorieux \& Thoen, 1998):

$$
\theta(\omega)=\frac{\left(1-e^{\sigma_{p} l_{p}}\right)(1+b)+\left(e^{-\sigma_{p} l_{p}}-1\right)(1-b)}{(1+b)^{2} e^{\sigma_{p} l_{p}}-(1-b)^{2} e^{-\sigma_{p} l_{p}}}
$$

Where $\theta(\omega)$ is the pyroelectric detector output signal $l_{p}$ is the pyroelectric thickness, $b=e_{s} / e_{p}$ with $e_{\mathrm{s}}$ and $e_{\mathrm{p}}$, the thermal effusivities for sample and pyroelectric respectively.

Substances with high thermal diffusivity rapidly adjust their temperature to that of their surroundings because they conduct heat quickly in comparison to their volumetric heat capacity that means that do not require much energy from their surroundings to reach thermal equilibrium (Eckert, 1987), materials with high thermal diffusivity are suitable to be use in the pyroelectric detectors, table 2 shows thermal diffusivity and thermal effusivity values for BNBT ceramics as well as BIT thermal values for comparison porpoises ( $\mathrm{He} \mathrm{Yi}$, 2004; Flores et al., 2008).

\begin{tabular}{lll}
\hline Material & $\mathrm{a}\left(\mathrm{cm}^{2} \mathrm{~s}^{-1}\right)$ & $e\left(\mathrm{Ws}^{1 / 2} \mathrm{~cm}^{-1} \mathrm{~K}^{-1}\right)$ \\
\hline $\mathrm{BaTiO}_{3}$ & 0.0103 & 0.2623 \\
$\left(\mathrm{Bi}_{0.5} \mathrm{Na}_{0.5}\right)_{0.935} \mathrm{Ba}_{0.065} \mathrm{TiO}_{3}$ & 0.0154 & 0.277
\end{tabular}

Table 2. Room temperature thermal difussivity $(\alpha)$ and thermal effusivity $(e)$ of BNBT and $\mathrm{BaTiO}_{3}$ ceramic materials 


\section{Ultrasound application}

An array of eight ultrasonic transducers was made in octagon form in order to be able for scan, from different ways, the object under study. The ultrasonic chamber design is as follows: a dielectric layer is placed at the top of the transducer, next is the ceramic with its respective electric contact immediately other ceramic without poling is iusing as backing material finally the transducer cover is put, Fig 10 shows a octagon schematic and a ultrasonic transducer detail, this design was repeated in everyone of the sides of the octagon. The distance between transducers is $120 \mathrm{~mm}$.

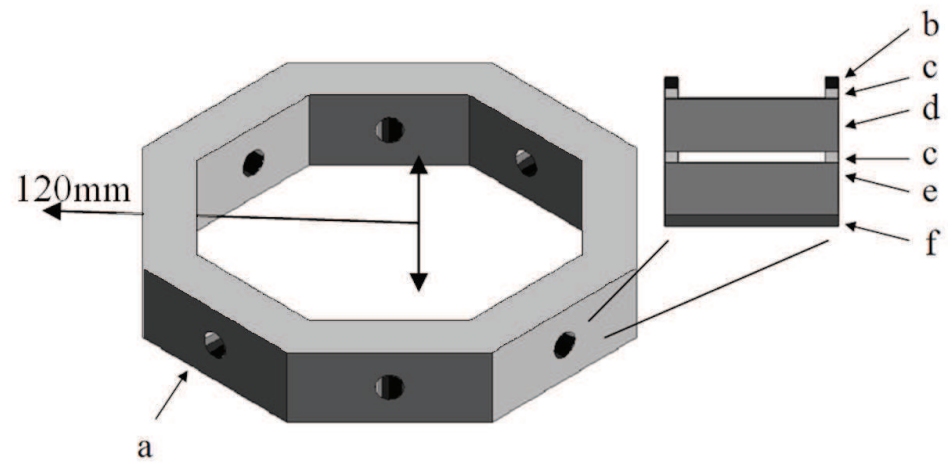

Fig. 10. Ultrasonic octagon schematic representation and ultrasonic transducer detail, a) ultrasonic transducer, b) isolating material, c) electrode, d) Piezoelectric ceramic, e) ceramic as backing, f) cover

A control circuit was design in order to get a electrical signal for be applied to the ceramic, this circuit has three parts: short pulses generator made with a microcontroller, a preamplifier and a power amplifier; microcontroller provides a pulses train with eight pulses and $5 \mathrm{~V}$ amplitude, the preamplifier increases this signal to $12 \mathrm{~V}$ amplitude and finally, the power amplifier give us a signal with $160 \mathrm{~V}$ amplitude, Fig 11 shows circuit control schematic diagram.
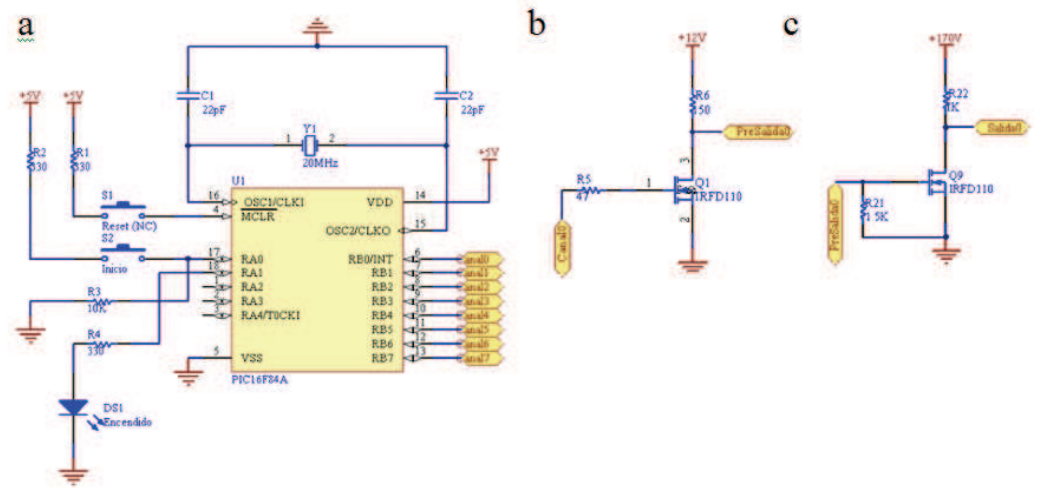

Fig. 11. Schematic design of circuit control, a) microcontroller, b) preamplifier, and c) power amplifier 
Function probes were made by applying a pulse train signal with amplitude of $160 \mathrm{~V}$ peak to peak and $555 \mathrm{kHz}$ of frequency, (as Fig 12 shown); to one of the transducers (Tx) while monitoring the response by other ceramic of the array $(\mathrm{Rx})$. The transmission medium was air, water, iron, and human leg.

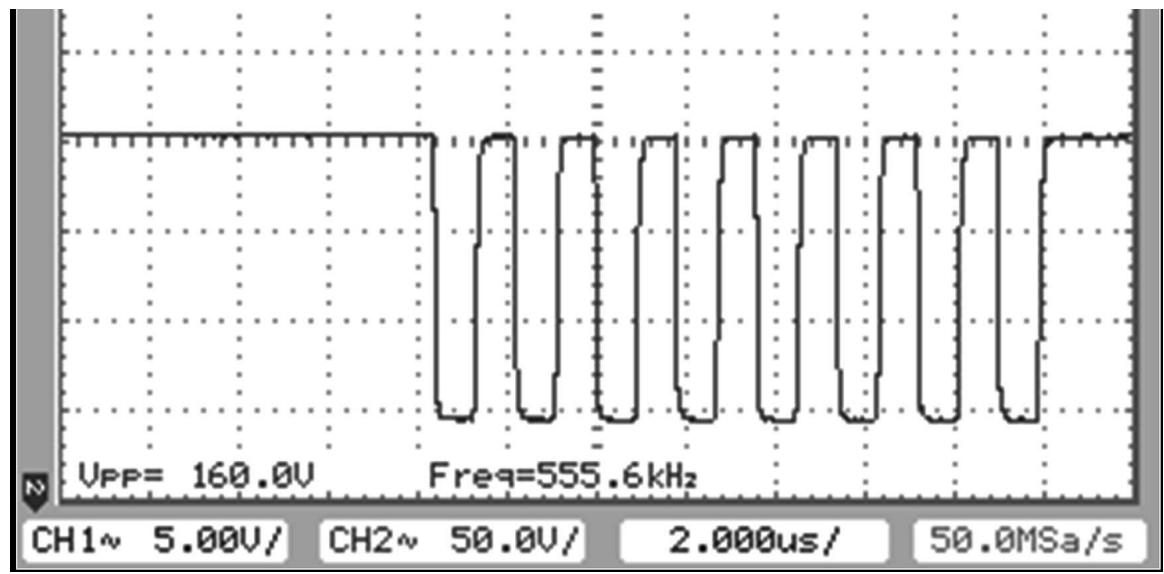

Fig. 12. Excitation signal applied to the piezoelectric ceramic

An aluminum transducer was made following the design showed in Fig 10, the final transducer is illustrated in Fig 13, at left is possible to see the complete transducer, at right a transducer detail in which is possible to see electrical contacts, acoustic isolation and spring to maintain all components in its respective place.
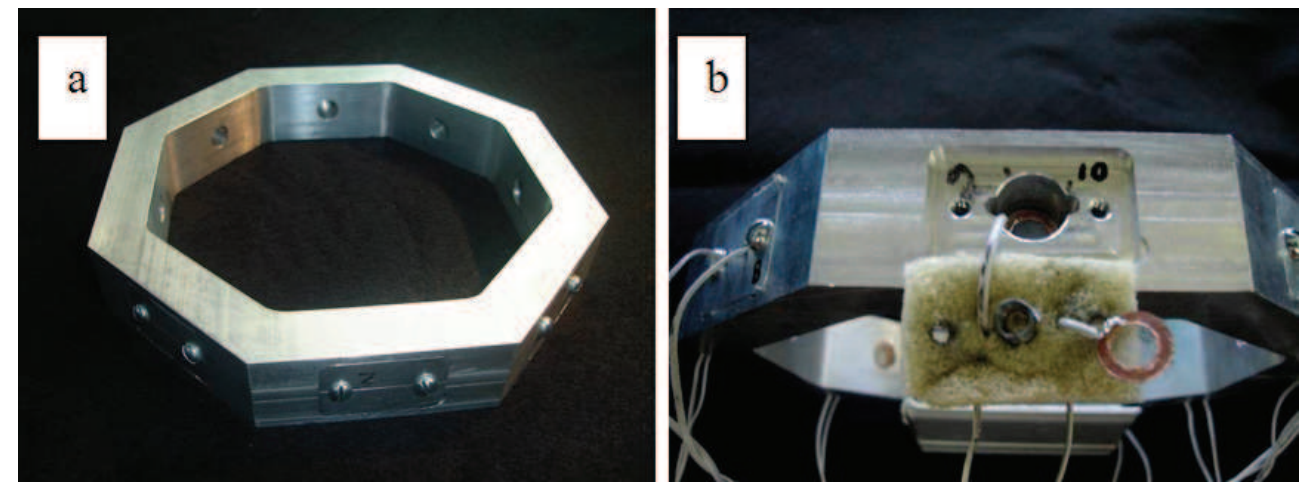

Fig. 13. a) Octagon for the ceramics and b) ultrasound transducer detail

Several materials were occupied to fill the transducer cavity in order to probe the ceramic emission and reception when the ultrasonic signal pass thought mediums with different densities, Fig 14 shows the experimental setup for ultrasound transmission in which is possible to see the octagon containing jelly while ultrasound pulse is applied.

Table 3 shows amplitude signals in an octagon array when a ceramic acts as emitter, and other ceramic in the opposite side acts as receiver, the array was filled with 
different propagation mediums, table also shows medium density as well as acoustic impedance.

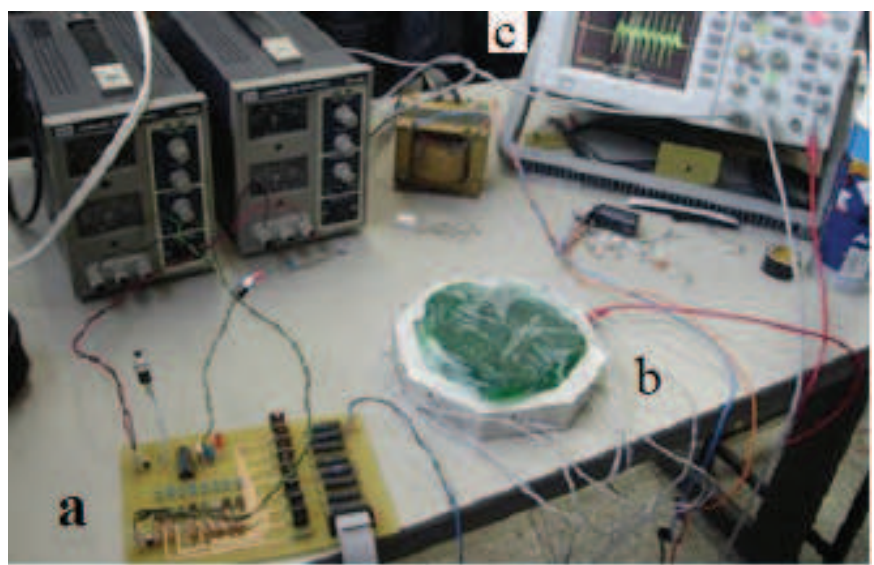

Fig. 14. Experimental setup use for ultrasound transmission, a) circuit control, b) octagon containing jelly and, c) signal obtained

\begin{tabular}{llll}
\hline $\begin{array}{l}\text { Transmission } \\
\text { medium }\end{array}$ & $\begin{array}{l}\text { Signal } \\
\text { Amplitude }(\mathrm{V})\end{array}$ & $\begin{array}{l}\text { Density } \\
\left(\mathrm{kg} / \mathrm{m}^{3}\right)\end{array}$ & $\begin{array}{l}\text { Acoustic Impedance } \\
\left(\mathrm{kg} / \mathrm{m}^{2} \mathrm{~s}\right)\end{array}$ \\
\hline Air & 1.54 & 1.3 & 446 \\
Water & 1.8 & 1000 & $1.493 \times 10^{6}$ \\
Iron & 1.2 & 1380 & $2.036 \times 10^{6}$ \\
Human Leg & 0.8 & 1070 & $1.62 \times 10^{6}$
\end{tabular}

Table 3. Signal amplitude obtained with different transmission medium

The transmitter was exited with a $160 \mathrm{~V}$ p-p signal and opposite side ceramic was used as receiver, different propagation mediums were placed filling the octagonal array, differences among signals gotten can be shown in Fig 15, attenuation in the received signal give us an idea of the density of propagation medium, it can be seen that amplitude and signal form are different. This is useful at the processing signal.

Signal showed in Fig 15 were digital processed and its spectral content were obtained as shown in Fig 16, spectra by each transmission medium was obtained by get the FFT of signals received. Differences in spectral content are due to medium scattering properties, for a solid and homogeneous transmission medium as iron the frequency spectrum contains only frequency components near to the excitation frequency that are reflected as one principal lobe in its spectrum as Fig 16c shows, for those materials with high scatter properties (human leg in our case), spectrum has more frequencies which can be seen as many peaks in frequency spectrum, as in Fig 16d case. 

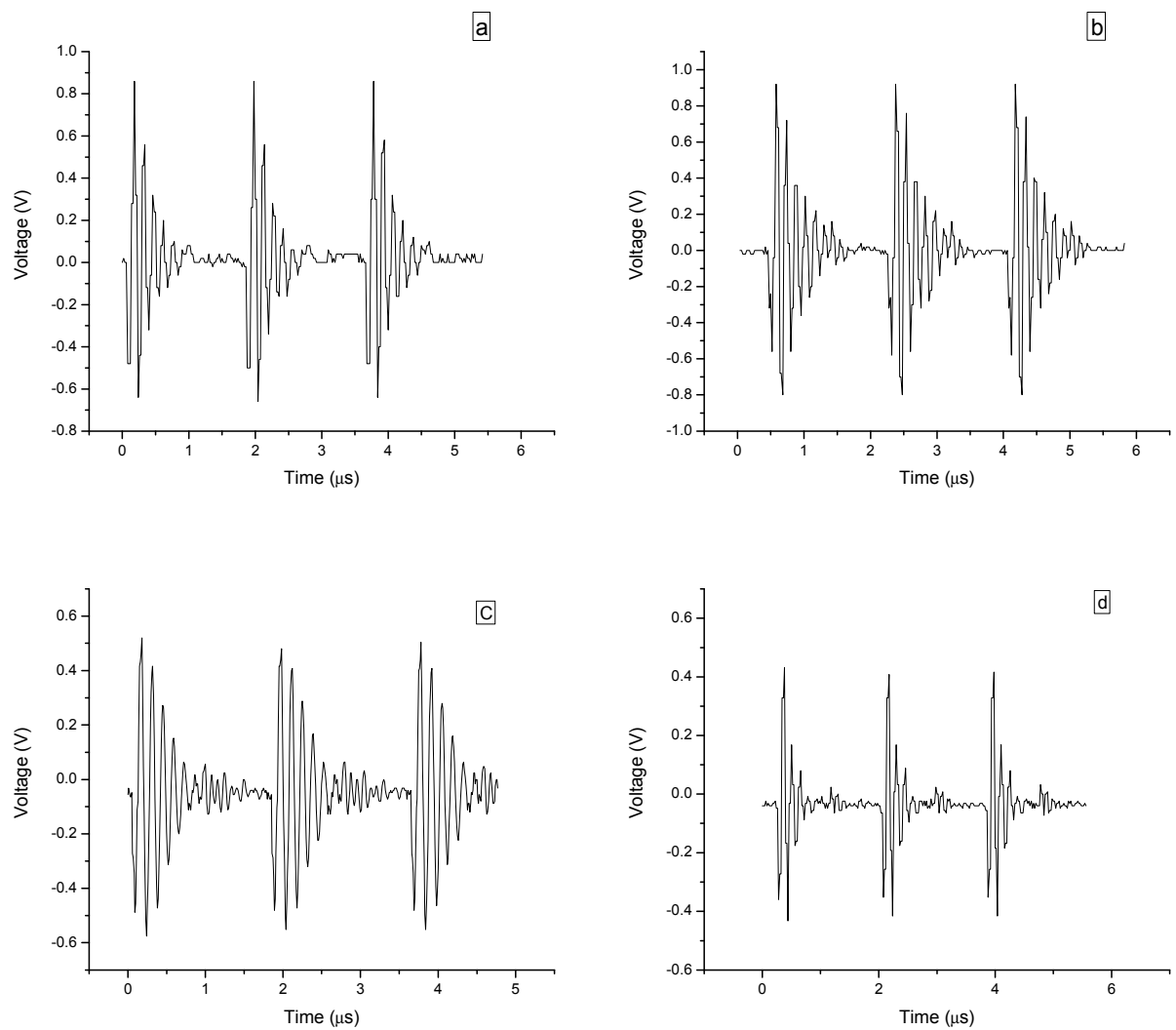

Fig. 15. Signals from octagon with different transmission medium, a) air, b) water, c) iron, and d) leg

\section{Conclusions}

Ceramics with formulation $\left(\mathrm{Bi}_{0.5} \mathrm{Na}_{0.5}\right)_{0.935} \mathrm{Ba}_{0.065} \mathrm{TiO}_{3}$ were obtained, electrical, thermal and optical characterization was made, a transducer based on this material was design and an application on ultrasound field was proposed. The ceramic properties were measured in order to characterize the piezoelectric ceramic.

SEM micrographs join with ceramic density revels compact structure that makes this ceramic suitable for develop ultrasound transducers and piezoelectric devices. This ceramic presents similar characteristics, as high $\mathrm{T}_{\mathrm{c}} 425^{\circ} \mathrm{C}$, high resonance frequency, that PZT shows, so it is an excellent candidate to substitute those ceramics made with lead, thermal properties are similar to BIT, XRD pattern is in agreement with the literature.

It was probed that ceramic presents electrical response when it is stimulated with light with length wave ranging from near UV to visible light, further probes need to be made to determine if this type of ceramics not only have electrical response under the stimulation of near UV but also in far UV. 

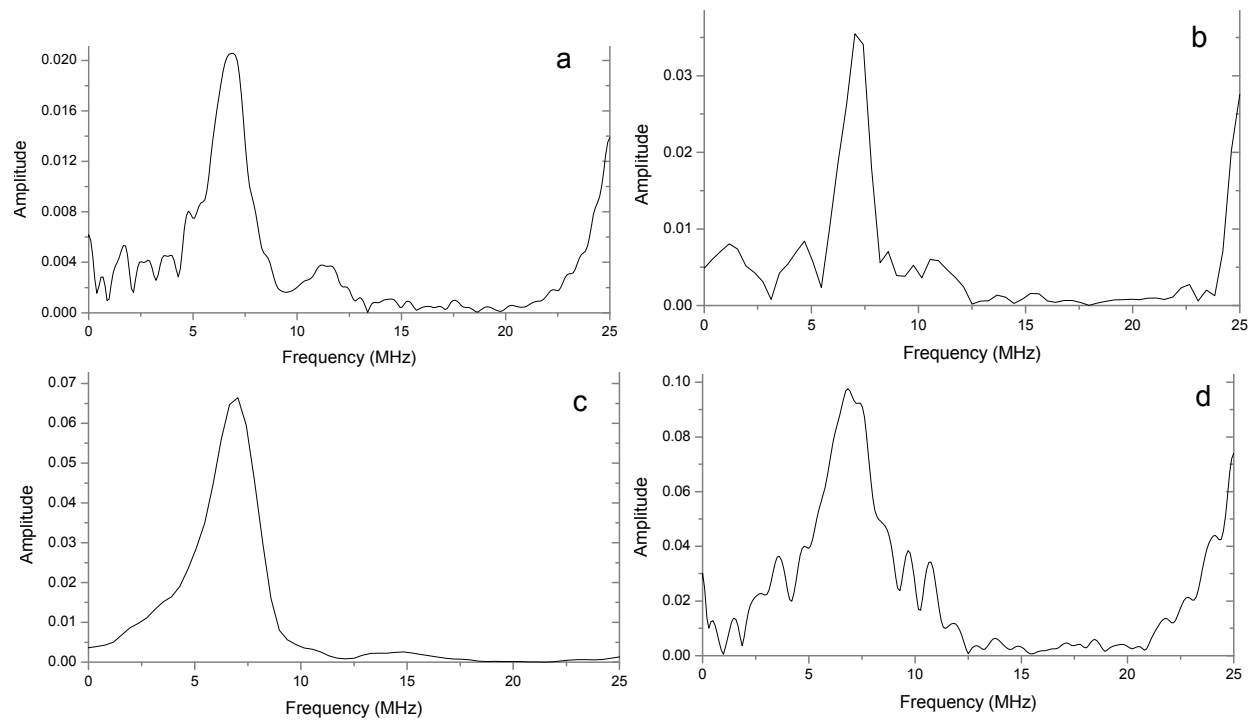

Fig. 16. Frequency spectrums obtained from signals received by Rx with different transmission medium, a) air, b) water, c) iron, and d) leg

Signals by the ceramic transducer acting as transmitter and receiver were obtained and differences in amplitude and form were found this is useful at the processing signal moment. Amplitude signals were in 0.8 and $2 \mathrm{~V}$ peak to peak range, this make easier detection and signal processing and make possible the use of this ceramic in pulse-echo mode A detection.

Since iron acoustic impedance is similar that $T x$, coupling impedance is good as its frequency spectra shows, whereas frequency spectra is different for each transmission medium that means an advantage for the image reconstruction.

This ceramic kind avoid environment contamination by the lead use and this first probes show its response in an ultrasound application.

For further work, some other electric and thermal characteristics of this material will be study in order to make a full characterization of BNBT ceramic. Also, the relaxor properties and its effect on the target application are going to be investigated.

\section{References}

Buhrer C. F. (1962). Some properties of bismuth perovskites, Journal of Chemical Physics 36, 798-803, 0021-9606

Byer R. L., Roundy C. B. (1972). Pyroelectric coefficient direct measurement technique and application to a NSEC response time detector, IEEE Trans sonics $\mathcal{E}$ ultrasound, 19, 333-338, 0018-9537

Caerels J., Glorieux C., and Thoen J. (1998). Absolute values of specific heat capacity and thermal conductivity of liquids from different modes of operation of a simple photopyroelectric setup, review of scientific instruments, 69(6), 2452-2458, 10897623 
Calderon A., Alvarado Gil J. J., Gurevich Y. G., Cruz Orea A., Delgadillo I., Vargas H., Miranda L. C. M. (1997). Photothermal Characterization of Electrochemical Etching Processed n-Type Porous Silicon, Physics Review Letters, 79, 5022 - 5025, 0031-9007

Cruz-Orea A., Delgadillo I. , Vargas H., Pichardo J. L., Alvarado-Gil J. J., Miranda L. C. M. (1996). On the Use of the Photoacoustic Technique for the Measurements of the Thermomechanical Properties of Semiconductor Two-Layers Systems, Solid State Communications, 100(12), 855-859, 0038-1098

Eckert E. R. G. (1987). Analysis of heat and mass transfer, Hemisphere, Pub. Corp., 0070189250

Efimovich I. (1964). Ultrasound physical, chemical, and biological effects, Consultants Bureau, New York

Flores-Cuautle J. J. A., Cruz-Orea A., and Suaste-Gomez E. (2008). Determination of Thermal Diffusivity and Thermal Effusivity of the $\left(\mathrm{Bi}_{0.5} \mathrm{Na}_{0.5}\right)_{0.935} \mathrm{Ba}_{0.065} \mathrm{TiO}_{3}$ Ferroelectric Ceramics by Photothermal Techniques, Ferroelectric Letters, 35, 136-143, 0731-5171

He Yi (2004). Heat capacity, thermal conductivity, and thermal expansion of barium titanate-based ceramics, Thermochimica acta, 419, 135-141, 0040-6031

IRE Standard on piezoelectric crystals: Measurements of piezoelectric ceramics. 1961. IRE Proceedings, 1161-1169

Jaeger R E and Egerton L. (1962). Hot Pressing of Potassium-Sodium Niobates. Journal of American Ceramics Society, 962, 45, 209-213, 1551-2916

Jaffe B., Cook W. R., Jaffe H. (1971). Piezoelectric Ceramics, Academic Press, 1878907107, London

Lines M. E., and Glass A. M. (1979). Principles and applications of ferroelectrics and related materials, Clarendon Press, 0-19-852003-4, Oxford

Liu S. T., Zook J. D., and Long D. (1975). Relationships between pyroelectric and ferroelectric parameters, Ferroelectrics, 9, 39-43, 0015-0193

Marquezini M. V., Cella N., Manzanares A. M., Vargas H., and Miranda L. C. M., (1991). Open photoacoustic cell spectroscopy, Measurement Science and Technology, 2. 396401, 0957-0233

Onoe M., Thiersen H. F. (1963). Shift in the location of resonance frequencies caused by large electromechanical coupling in thickness-mode resonator, Journal of acoustical society of America, 35(1), 0001-4966

Rajeev Ranjan R., and Dviwedi A., (2005). Structure and dielectric properties of $\left(\mathrm{Na}_{0.50} \mathrm{Bi}_{0.50}\right)_{1-x} \mathrm{Ba}_{\mathrm{x}} \mathrm{TiO}^{3}: 0 \leq \mathrm{x} \leq 0.10$. Solid State Communications, 135(6), 394-399, 0038-1098

Rodríguez-Ruiz R., Gonzalez-Ballesteros R., Flores-Cuautle J. J. A., and Suaste-Gomez E. (2008). Determination of the Pyroelectric Coefficient of the $\left(\mathrm{Bi}_{0.5} \mathrm{Na}_{0.5}\right)_{0.935} \mathrm{Ba}_{0.065} \mathrm{TiO}_{3}$, Ferroelectrics 368, 216-223, 0015-0193

Rosencwaig A. (1980). Photoacoustic and Photoacoustic spectroscopy, John Wiley \& sons Inc., 0894644505, New York

Sasaki A., Chiba T., Mamiya Y., and Otsuki E. (1999). Dielectric and Piezoelectric Properties of $\left(\mathrm{Bi}_{0.5} \mathrm{Na}_{0.5}\right) \mathrm{TiO}_{3}-\left(\mathrm{Bi}_{0.5} \mathrm{~K}_{0.5}\right) \mathrm{TiO}^{3}$ Systems, Japan Journal of Applied Physics, $38(9 \mathrm{~B})$, 5564-5567, 0021-4922

Smollenky G. A., Isupov V. A., Agranovkaya A. I., and Krainik N. N. (1961). New Ferroelectrics of complex composition. Soviet Physics Solid State, 2, 2651-2654, 00385654 
Suaste-Goméz E. \& González-Moran C. O. (2009). Photovoltaic Effect of Lead-Free Piezoelectric Ceramics, $\left(\mathrm{Bi}_{0.5} \mathrm{Na}_{0.5}\right)_{0.935} \mathrm{Ba}_{0.065} \mathrm{TiO}_{3}$ and $\mathrm{Pb}_{0.88}(\mathrm{Ln})_{0.08} \mathrm{Ti}_{0.98} \mathrm{Mn}_{0.02} \mathrm{O}_{3}$ ( $\mathrm{Ln}$ $=\mathrm{La}, \mathrm{Eu})$, Ferroelectrics, 386, 70-76, 0015-0193

Takenaka T., Maruyama K. I., and Sakata K. (1991). ( $\left(\mathrm{Bi}_{0.5} \mathrm{Na}_{0.5}\right) \mathrm{TiO}_{3}-\mathrm{BaTiO}_{3}$ System for LeadFree Piezoelectric Ceramic, Japan Journal of Applied Physics 30(9B), 2236-2239, 00214922

Takenaka T., Sakata K., and Toda K. (1989). Acoustic Wave Characteristics of Lead-Free $\left(\mathrm{Bi}_{1 / 2} \mathrm{Na}_{1 / 2}\right)_{0.99} \mathrm{Ca}_{0.01} \mathrm{TiO}_{3}$ Piezoelectric Ceramic, Japan Journal of Applied Physics 28(282), 59-62, 0021-4922

Uchino K. (2000). Ferroelectric Devices, Marcel Dekker, Inc., New York, United States

Weihua Liu, Qing Xu, Wen Chen, Min Chen and Bokhee Kim (2008). Structure and electrical properties of (Na0.5Bi0.5)0.94Ba0.06TiO3 ceramic with $0.5 \mathrm{wt} \%$ of $\mathrm{MnO}$, Journal of Wuhan University of Technology-Mater. Sci. Ed. 23(4), 499-502, 1000-2413 


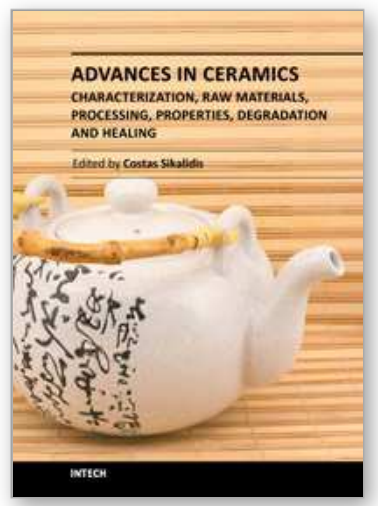

\author{
Advances in Ceramics - Characterization, Raw Materials, \\ Processing, Properties, Degradation and Healing \\ Edited by Prof. Costas Sikalidis
}

ISBN 978-953-307-504-4

Hard cover, 370 pages

Publisher InTech

Published online 01, August, 2011

Published in print edition August, 2011

The current book consists of eighteen chapters divided into three sections. Section I includes nine topics in characterization techniques and evaluation of advanced ceramics dealing with newly developed photothermal, ultrasonic and ion spattering techniques, the neutron irradiation and the properties of ceramics, the existence of a polytypic multi-structured boron carbide, the oxygen isotope exchange between gases and nanoscale oxides and the evaluation of perovskite structures ceramics for sensors and ultrasonic applications. Section II includes six topics in raw materials, processes and mechanical and other properties of conventional and advanced ceramic materials, dealing with the evaluation of local raw materials and various types and forms of wastes for ceramics production, the effect of production parameters on ceramic properties, the evaluation of dental ceramics through application parameters and the reinforcement of ceramics by fibers. Section III, includes three topics in degradation, aging and healing of ceramic materials, dealing with the effect of granite waste addition on artificial and natural degradation bricks, the effect of aging, micro-voids, and self-healing on mechanical properties of glass ceramics and the crack-healing ability of structural ceramics.

\title{
How to reference
}

In order to correctly reference this scholarly work, feel free to copy and paste the following:

E. Suaste Gómez and J. J. A. Flores Cuautle (2011). Lead Free BNBT Type Ceramics: A Useful Material for Sensors and Ultrasound Applications, Advances in Ceramics - Characterization, Raw Materials, Processing, Properties, Degradation and Healing, Prof. Costas Sikalidis (Ed.), ISBN: 978-953-307-504-4, InTech, Available from: http://www.intechopen.com/books/advances-in-ceramics-characterization-raw-materials-processingproperties-degradation-and-healing/lead-free-bnbt-type-ceramics-a-useful-material-for-sensors-andultrasound-applications

\section{INTECH}

open science | open minds

\author{
InTech Europe \\ University Campus STeP Ri \\ Slavka Krautzeka 83/A \\ 51000 Rijeka, Croatia \\ Phone: +385 (51) 770447 \\ Fax: +385 (51) 686166 \\ www.intechopen.com
}

\author{
InTech China \\ Unit 405, Office Block, Hotel Equatorial Shanghai \\ No.65, Yan An Road (West), Shanghai, 200040, China \\ 中国上海市延安西路65号上海国际贵都大饭店办公楼 405 单元 \\ Phone: +86-21-62489820 \\ Fax: +86-21-62489821
}


(C) 2011 The Author(s). Licensee IntechOpen. This chapter is distributed under the terms of the Creative Commons Attribution-NonCommercialShareAlike-3.0 License, which permits use, distribution and reproduction for non-commercial purposes, provided the original is properly cited and derivative works building on this content are distributed under the same license. 